\title{
Modelling irrigated sugarcane crop under seasonal climate variability: A case study in Burdekin district
}

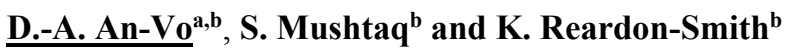 \\ ${ }^{a}$ University of Southern Queensland, Computational Engineering and Science Research Centre, \\ Toowoomba, QLD 4350, Australia \\ ${ }^{b}$ University of Southern Queensland, International Centre for Applied Climate Sciences, Toowoomba, QLD \\ 4350, Australia \\ Email:duc-anh.an-vo@usq.edu.au
}

\begin{abstract}
Sugarcane industries worldwide are exposed to uncertainty associated with weather and seasonal climate variation. This variability often impacts negatively on crop production, leading to conservative farming strategies that sacrifice productivity in order to reduce the risk of losses in poor years. The situation is especially severe in Australia where sugarcane production is subject to an extremely variable climate. Inter-annual variability in climatic properties in Australia is about $15-18 \%$ higher than any other major agricultural nation. In such an extremely variable environment, knowledge of crop performance under different climate conditions and use of seasonal climate forecasts in decision making can play an important role in supporting agricultural risk management.
\end{abstract}

Here, we quantified the effect of seasonal climate variability on sugarcane performance under rain-fed conditions and irrigation by integrating the long term climate data record into a crop model, the Agricultural Production Systems SIMulator (APSIM) Sugar, which was calibrated using case study information for the Burdekin sugarcane production region. Two irrigation schedules of five and 20 days were simulated for a range of irrigation water volumes applied in each irrigation event to the plant crop and four ratoons to study the effect of irrigation timing. We conducted economic analyses to convert biophysical yield results into economic returns which were classified according to annual precipitation terciles i.e. wet, normal, and dry climate conditions. This framework allowed us to identify optimal irrigation strategies to achieve maximum yield or economic return under different climate conditions.

The results showed that seasonal climate has a strong influence on crop performance and cash flow in both rain-fed and irrigated sugarcane in the Burdekin region. The case study example was not economically viable under normal and dry climate conditions for either the rain-fed or limited water volume simulations, which indicates the significant importance of using seasonal climate forecasts in irrigation scheduling decisions. Different optimal irrigation strategies associated with different climate conditions were observed for all cropping stages (i.e. the plant crop and four ratoons). Results also showed that more regular irrigation resulted in better water use efficiency in terms of both yield and economic benefits. Yield and economic benefit increases for the 5 day irrigation schedule can be up to AUD $40 \mathrm{t} \mathrm{ha}^{-1}$ and AUD $1000 \mathrm{ha}^{-1}$, respectively, compared with those for the 20 days schedule.

Keywords: Sugarcane, seasonal climate, irrigation, decision support, APSIM Sugar 


\section{INTRODUCTION}

Sugarcane is a crop plant that originated in the wet tropics. Therefore, to achieve maximum productivity, it requires an abundant supply of water, supplied either as rainfall, by irrigation or a combination of these. The need for irrigation has long been recognised in the Burdekin, Bundaberg and Central sugarcane growing regions of coastal Queensland, Australia, where groundwater and surface water sources have been used to supplement rainfall since the late 1890s. Drought years around that time proved the importance of a regular water supply for sugarcane production and gave rise to ongoing interest and investment in irrigation systems. However, the long term economic viability of irrigating sugarcane, taking into account the net present value for various benefit and cost streams (e.g. Mushtaq and An-Vo et al., 2017), is not generally considered.

With suitable conditions of adequate temperature and sunlight, sugarcane grows in direct proportion to the amount of water available. For each $100 \mathrm{~mm}$ of soil water (provided by irrigation or rainfall) used by the crop, approximately ten tonnes per hectare of sugarcane is produced (Russell, 1990; SRA, 2014), while highly water use efficient irrigation practices can produce up to 20 tonnes of sugarcane per hectare using the same amount of water (Inman-Bamber et al., 1999). Growth measurements of over $40 \mathrm{~mm}$ per day have been recorded under conditions of adequate moisture, sunlight and temperature (over $24^{\circ} \mathrm{C}$ ). As moisture is removed from the soil by evapotranspiration, growth rates decline rapidly in response to increasing moisture stress (SRA, 2014). Crop yield responses to irrigation vary between districts because of climatic and edaphic conditions.

The sugarcane crop cycle comprises growing and annual harvesting of the crop over a four to five year period, with regrowth stages in years $2-5$ called 'ratoons'. Due to the cost of planting operations in year 1 , ratoon crops are often more economically reliable and in some cases the number of ratoons may be increased before the crop is replanted. Irrigation can increase sugarcane yields and the sustainability of crop production by reducing dependence on uncertain rainfall. Irrigation also allows for better planning and increased flexibility of farming activities. With irrigation, growers have more flexibility in deciding when to plant a crop since they are not reliant on rainfall to provide soil moisture. However, the cost of irrigation water is rising due to pressure from other sectors, environmental issues and increased energy prices (An-Vo and Mushtaq et al., 2015a\&b). In addition, excess water may cause waterlogging which will not only reduce sugarcane yields but may also be associated with increased irrigation costs. Therefore, improving water use efficiency by appropriate irrigation scheduling is important under a range of crop water use conditions to ensure the profitability and general sustainability of the sugarcane sector. Waiting for the crop to begin to show moisture stress or irrigating on a set cycle can lead to inefficient water use and lower yields and economic returns.

Sugarcane crop production, irrigation and climate variability are thus closely related. There is an urgent need to tailor sugarcane irrigation practices to suit different climate conditions across Queensland's sugarcane production regions, which are noted for their extreme variability (e.g. Nguyen-Huy and Deo et al., 2017). Knowledge of possible crop yields and economic returns under different climate conditions, in addition to improved use of seasonal climate forecasts, will enable growers to make better irrigation scheduling decisions. Here, we employed the Agricultural Production Systems SIMulator (APSIM) Sugar, calibrated using case study information, to simulate crop production under different climatic conditions and irrigation scheduling scenarios. We then analysed crop yields and economic returns under precipitation terciles (i.e. dry, normal, and wet conditions) based on historical rainfall records. Optimal irrigation schedules achieving both maximum yield and profit for plant and ratoon crops were identified for the different climate conditions. The results have important implications for climate risk management and adaptation to projected climate changes at farm level.

\section{METHODOLOGY}

\subsection{Sugarcane growth simulation in APSIM}

Sugarcane yields were simulated using the sugar module in APSIM (Keating et al., 2003); hereafter, APSIM Sugar. APSIM is a daily time-step model and requires daily climate data. Daily climate data, developed by Jeffrey et al. (2001), was obtained from the SILO database (http://www.longpaddock.qld.gov.au/silo). Historical daily maximum and minimum temperature, solar radiation and rainfall data were obtained from the Ayr DPI research station (Bureau of Meteorology site number 33002) for the 1889-2015 period which is also the crop simulation period.

In the model simulation, sugarcane was planted at a stalk density of $10 \mathrm{plants} / \mathrm{m}^{2}$ on 30 April at the beginning of each 6-year crop cycle, which included one plant crop (15 months) and four ratoon crops (13 months each). An amount of $100 \mathrm{~kg} \mathrm{ha}^{-1}$ urea was applied at sowing and on a fixed day ( $1^{\text {st }}$ September) every year which was tested to be sufficient to avoid yield impact due to nutrient limitation. The soil water and nutrient levels were reset at the beginning of each crop cycle. A modified crop cultivar was used in our simulations because (1) the 
default cultivars available in the standard release of APSIM-sugar are no longer (or barely) used on farms (QCANESelect ${ }^{\mathrm{TM}}$; Sugar Research Australia, 2017), and (2) preliminary analyses showed noticeable errors when comparing the simulated values to those for our case study in the Burdekin region (see below). The modified crop parameters, as well as a comparison of simulation errors, are provided in supplementary Table 1 and Figure 1. Pests, diseases, and weeds were not simulated and it was assumed that the grower would take all reasonable steps to control these in any case. Simulations were performed on a silty clay loam soil, the case study soil type, retrieved from the APSoil database (Dalgliesh et al., 2012).

Table 1. Ranges of selected variety parameters as reported in the standard release of APSIM-Sugar, and modifications performed in our analyses. The modifications applied both to the plant crop and ratoons.

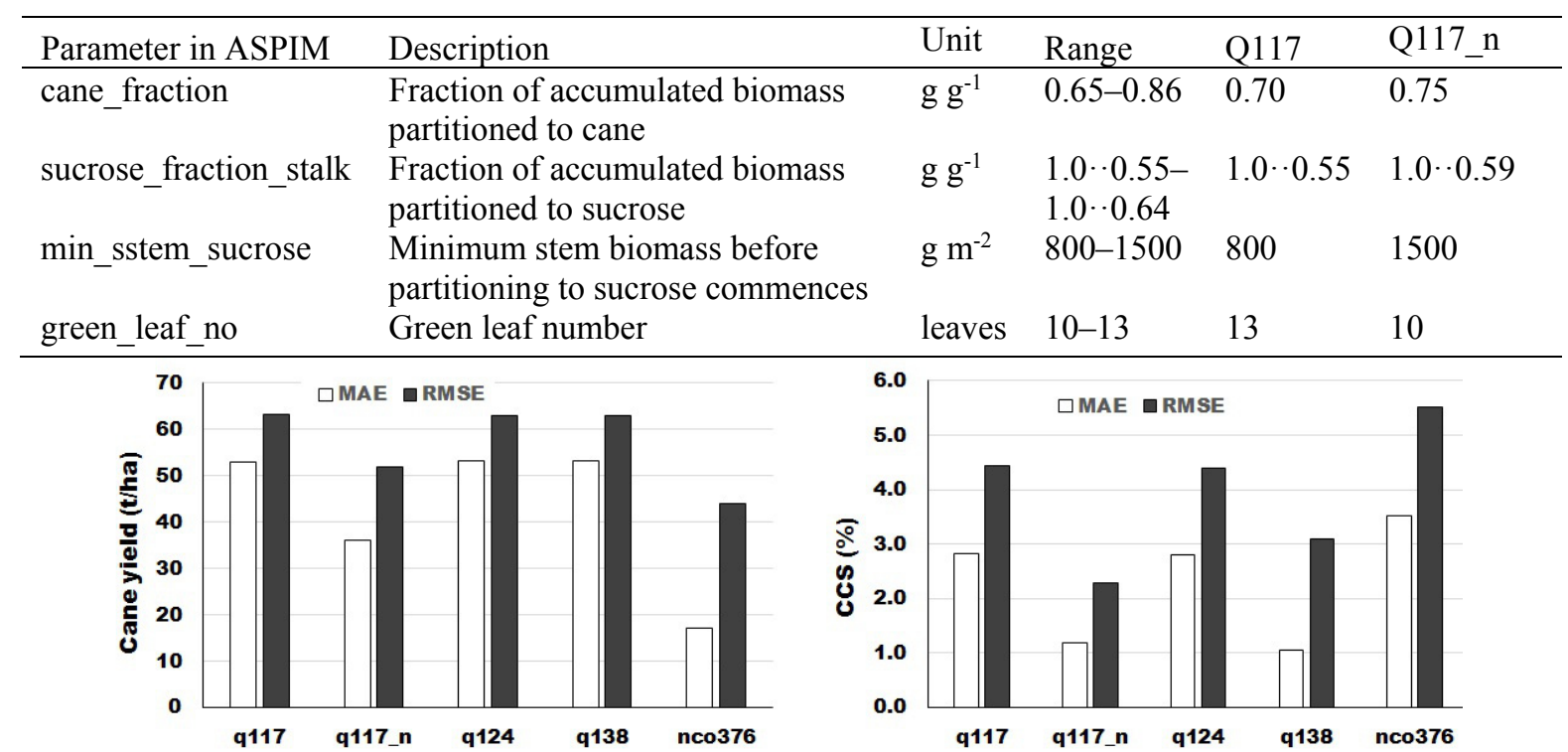

Figure 1. Sensitivity analysis results for different sugar cultivars using APSIM. The mean absolute error (MAE) and root mean square error (RMSE) between observed and predicted cane yield (left) and CCS (right) are presented. q117, q124, q138 and nco376 are default sugar cultivar; q117_n refer to the cultivar with modified parameters as reported in Table 1.

The irrigation schedule and amount was set according to the readily available water for the soil type and the daily crop water use. In our simulations, irrigation water amounts ranging from 0 up to $120 \mathrm{~mm}$ were applied every 5 and 20 days from planting to harvest.

\subsection{Integrated bio-economic assessment}

We integrated APSIM Sugar simulations with profit functions, using an integrated bio-economic model, to derive gross margins and yield relationships by systematically varying irrigation levels under different climate conditions (Power and Cacho, 2014). The profit function of sugarcane represents the net return after subtracting the input cost and water cost from income (An-Vo et al., 2015) under different climate conditions, given by

$$
P(W)=p \times Y(W)-p_{h} \times Y(W)-C-p_{w} \times W
$$

where $P(W)$ is the water-profit function and $Y(W)$ the associated water-yield production function under the three climate conditions, i.e. dry, normal, and wet; $p$ is the cane price (AUD $39 \mathrm{t}^{-1}$; adapted from Valle and Martin, 2015; $p_{h}$ is the harvesting cost (AUD t ${ }^{-1}$ ); $C$ is the variable cost including the fertiliser cost; and $p_{w}$ is the water cost (AUD ML ${ }^{-1}$ ). In our case study interviews, we collected detailed variable costs per ha for plant crop and ratoons in the Burdekin region.

\section{THE BURDEKIN DISTRICT AS A CASE STUDY}

The Burdekin sugarcane growing district, located around Ayr in northern Queensland, Australia (Figure 2), has a low level of annual effective rainfall ( $450 \mathrm{~mm}$ on average) and hence benefits significantly from applied irrigation. In the Burdekin region, where good water storages are available, irrigation is used to meet sugarcane crop water requirements throughout the growing season to maintain crop yields. 
Burdekin sugarcane growers participating in this study generally schedule irrigation based on water deficit indices, experience and the logistics of their water delivery systems. Measurement/monitoring of soil water deficit or crop growth indices has typically resulted in irrigation on a regular 6-8 day cycle for the full sugarcane crop. To quote one of the growers interviewed: "You're looking at crop requirements all the time. So you're watering for crop requirements regardless of the type of season it's been." If it is a wet year, there may be very little irrigation. If dry weather is forecast, the highest priority for irrigation will be the newly planted crop, the 'plant cane', which has the biggest yield potential; this is followed by the early ratoons, then the late ratoons. For example, where there are limitations due to the water delivery system and there are three crop stages to be watered - the plant cane, a first and a second ratoon-watering will start with the plant cane, followed by the ratoons; if, halfway through watering the third ratoon, the plant cane or first ratoon is due for a watering again, irrigation of the older ratoon will stop and the cycle will be restarted.


Figure 2. The Burdekin sugarcane growing region in Queensland denoted by the green area around Ayr DPI climate station (red start).

\section{RESULTS AND DISCUSSION}

The crop growth simulation model was calibrated to capture observed sugarcane yields at farm and regional levels. Observed yields at farm level (2005-2016) were collected from our case study interviews while regional yield datasets (1942-2014) were supplied by Canegrowers Australia (http://www.canegrowers.com.au/). The observed yields were de-trended to remove the effects of technology and variety improvements. The calibrated APSIM Sugar model was firstly used to simulate crop growth under rain-fed conditions. The results for crop yields and gross margins show a strong influence of seasonal climate on crop performance and economic return (Figure 3). The largest yield gaps between wet and dry conditions (up to $50 \mathrm{t} \mathrm{ha}^{-1}$ ) were observed in Ratoon 1, Ratoon 2 and Ratoon 3 (Figure 3a). Given high production costs in the Burdekin district (Valle and Martin, 2015), likely negative economic returns under dry and normal conditions (Figure 3b) reflect the fact that rainfed sugarcane growing is not economically viable in the district and that irrigation is essential. Rain-fed sugarcane growing is viable only under wet seasonal climate conditions.
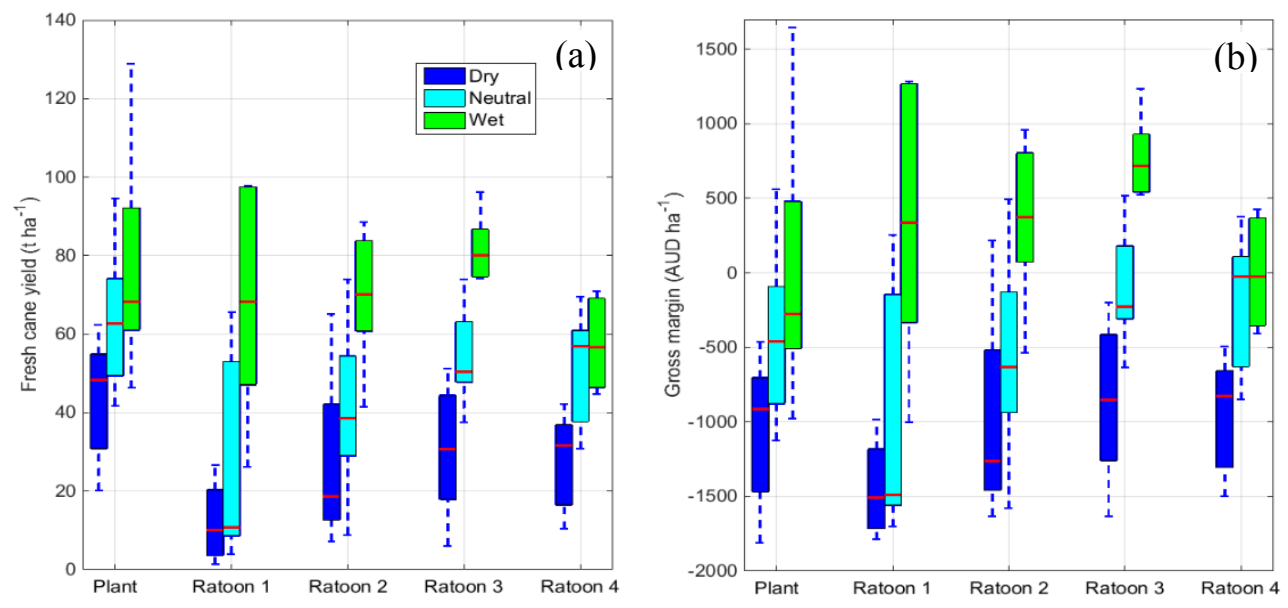

Figure 3. Fresh sugarcane yield and gross margin distributions for the plant crop and four ratoons under different climatic conditions for rain-grown sugarcane in the Burdekin district. 
Crop growth was simulated employing the prescribed irrigation scheduling strategy, i.e. by varying the irrigation water amount at each irrigation from a smallest value of $5 \mathrm{~mm}$. Time periods between irrigation applications were implemented at 5 days (Schedule 1) and 20 days (Schedule 2) to study the effect of irrigation timing. Irrigation water amount could be up to $50 \mathrm{~mm}$ in Schedule 1 and $120 \mathrm{~mm}$ in Schedule 2.

As expected, seasonal climate had a strong influence on crop yields at low irrigation water amounts (Figure 4) similar to the results for rain-fed cropping. With low irrigation water amounts, seasonal climate also had a more significant influence in the less frequent regular 20 day irrigation schedule (Schedule 2) than the more frequent irrigation schedule (Schedule 1).

In terms of yield potential, Schedule 1 showed significantly higher yield potentials for the plant cane and Ratoon 1 crops, slightly higher for Ratoons 2 and 3, and similar for the Ratoon 4 crop. Water use efficiencies were higher for the more frequent 5 day irrigation schedule (Schedule 1) in plant cane and Ratoon 1 crops. For the plant cane crop, average yields under Schedule 1 at $30 \mathrm{~mm}$ were about $200 \mathrm{t} \mathrm{ha}^{-1}$ while for a similar total water volume the average yields for Schedule 2 irrigation (at $120 \mathrm{~mm}$ ) were around $160 \mathrm{t} \mathrm{ha}^{-1}$. For the Ratoon 1 crop, yields were about $180 \mathrm{t} \mathrm{ha}^{-1}$ under Schedule 1 compared to around $160 \mathrm{ha}^{-1}$ for Schedule 2. This indicates more efficient water use under more frequent irrigation schedules, however, the effect differed between crop stages (Figure 4).

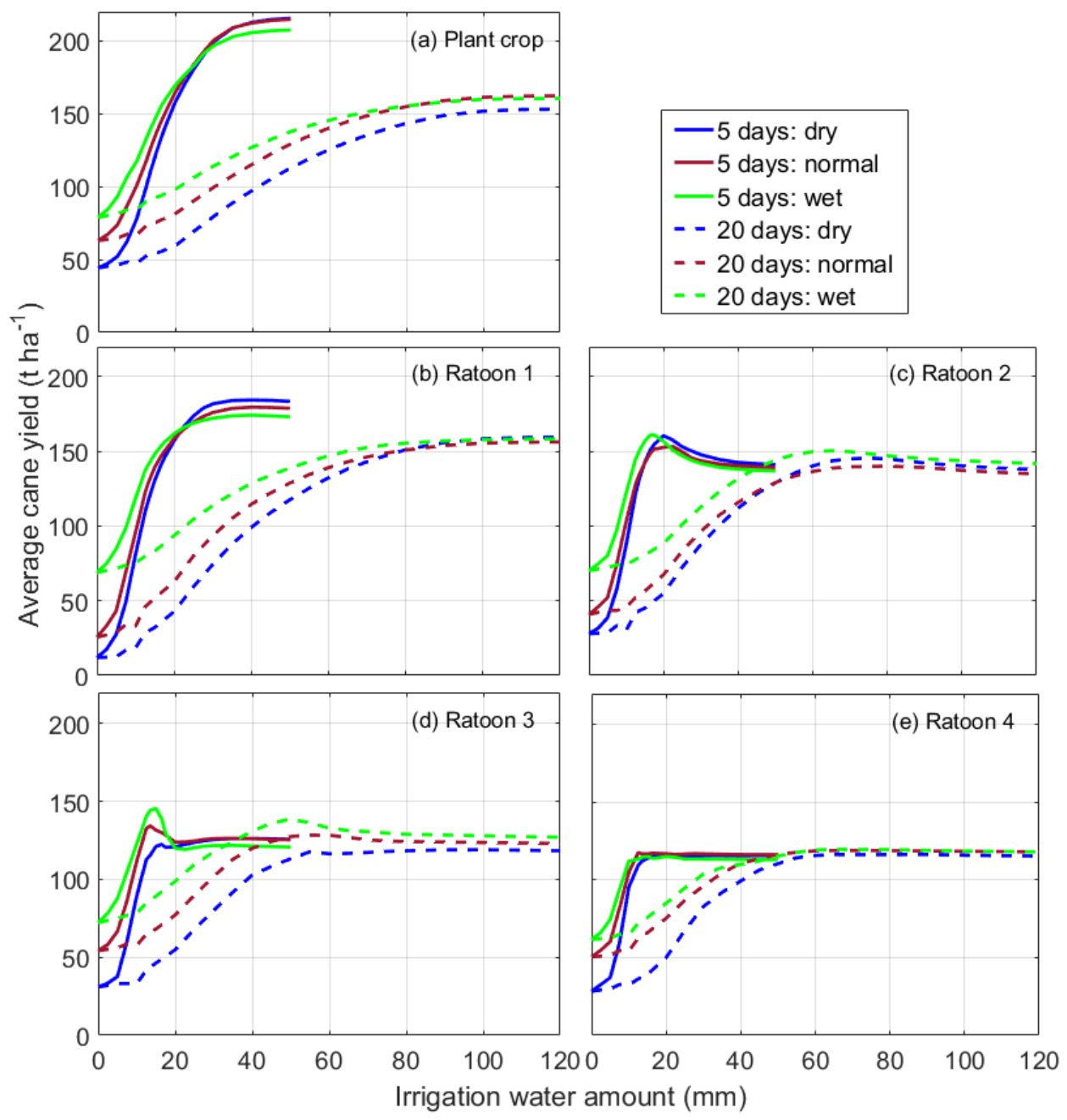

Figure 4. Average fresh sugarcane yield for the plant cane and four ratoons under three climatic conditions in irrigated sugarcane. Continuous lines are for Schedule 1 while the dashed lines are for Schedule 2.

In economic terms, while negative average gross margins were observed at small irrigation water amounts under normal and dry climate conditions (similar to rain-fed conditions), economic viability can be guaranteed in wet conditions for all plant crop and four ratoons (Figure 5). This highlights the importance of irrigation under normal and dry climate conditions in the Burdekin district. With the same water volume use, Schedule 1 showed potentially higher economic returns for the plant cane and ratoons 1, 2 and 3 compared to Schedule 2. Specifically, a potential gross margin increase of about AUD $1000 \mathrm{ha}^{-1}$ was simulated for the plant cane 
crop (Figure 5a), about AUD $400 \mathrm{ha}^{-1}$ for Ratoon 1 (Figure 5b), about AUD $300 \mathrm{ha}^{-1}$ for Ratoon 2 (Figure 5c), and about AUD $100 \mathrm{ha}^{-1}$ for Ratoon 3 (Figure 5d). These positive results were obtained without considering any possible additional costs (e.g. energy costs, capital costs of depreciation) of operating the irrigation system under the different irrigation schedules.



Figure 5. Average gross margin for the plant cane crop and four ratoons under three climatic conditions in irrigated sugarcane. Continuous lines are for Schedule 1 while the dashed lines are for Schedule 2.

Differences were also observed in the optimal irrigation water amounts needed for all crop stages (i.e. plant cane and four ratoons) to achieve maximum yield or maximum economic return (Figure 5) under the three climate conditions. This highlights the importance of tailoring irrigation strategies to climate conditions. Knowledge of optimal irrigation strategies under different climate conditions is essential for the use of seasonal climate forecast in irrigation decision making. The analysis presented in this paper shows the potential application of seasonal climate forecasts in sugarcane irrigation management, based on case study information collected from interviews with selected sugarcane farmers and industry experts in the Burdekin region, where current adoption and use of seasonal climate forecasts in irrigation scheduling is limited.

\section{CONCLUSION}

In this study, we presented a framework for tailoring sugarcane irrigation strategies under different climate conditions as essential knowledge for increased adoption and use of seasonal climate forecasts in irrigation decision making. The framework integrates historical climate observation data with a calibrated crop model (APSIM Sugar) and economic modelling to identify optimal strategies under different climate conditions to achieve maximum yields and economic returns. The results show that seasonal climate has a strong influence on crop performance and cash flow in rain-fed sugarcane production systems and in irrigated cropping systems 
where low water volumes are used in each irrigation event. Different optimal irrigation strategies were observed for all plant crop and four ratoons under the different climate conditions.

We also studied the effect of irrigation timing for two schedules of five and 20 days. Results show that more frequent irrigation provided better water use efficiency in terms of yield and potential economic benefits. Yield and economic benefits under irrigation Schedule 1 relative to Schedule 2 can be up to $40 \mathrm{tha}^{-1}$ and AUD 1000 $\mathrm{ha}^{-1}$ (without considering the energy and depreciation costs associated with an increased number of irrigation applications), respectively. It is important to emphasise that the results of this analysis should not be used as the criterion for irrigation decisions at the case study locations, as local conditions (e.g. soils and management) may not fit the assumptions made in the analysis. However, the methods employed, together with grower specifics, may be used when considering adoption of seasonal climate forecast or adaptation of projected changing climate on farm.

\section{ACKNOWLEDGEMENTS}

This research was funded by the Drought and Climate Adaptation Program and University of Southern Queensland. We acknowledge Dr Louis Kouadio for creating Figure 1, 2 and Table 1.

\section{REFERENCES}

An-Vo, D.-A., Mushtaq, S., Nguyen-Ky, T., Bundschuh, J., Tran-Cong, T., Maraseni, T. and Reardon-Smith, K. (2015a). Nonlinear optimisation using production functions to estimate economic benefit of conjunctive water use for multicrop production. Water Resources Management 29(7), 2153-2170.

An-Vo, D.-A., Mushtaq, S. and Reardon-Smith, K. (2015b). Estimating the value of conjunctive water use at a system level using nonlinear programming model. Journal of Economic and Social Policy 17(2), Article 9.

Dalgliesh, N.P., Cocks, B. and Horan, H. (2012). APSoil-providing soils information to consultants, farmers and researchers. In: Yunusa, I. (Ed.), 16th Australian Agronomy Conference 2012: Armidale, NSW.

Inman-Bamber, N., Robertson, M., Muchow, R., Wood, A., Pace, R. and Spillman, A. (1999). Boosting yields with limited irrigation water. Proceedings of the Australian Society of Sugar Cane Technologists 21, 203211.

Jeffrey, S.J., Carter, J.O., Moodie, K.B. and Beswick, A.R. (2001). Using spatial interpolation to construct a comprehensive archive of Australian climate data. Environmental Modelling \& Software 16(4), 309-330.

Keating, B.A., Carberry, P.S., Hammer, G.L., Probert, M.E., Robertson, M.J., Holzworth, D., . . . and Smith, C.J. (2003). An overview of APSIM, a model designed for farming systems simulation. European Journal of Agronomy 18(3-4), 267-288.

Mushtaq, S., An-Vo, D.-A., Christopher, M., Zheng, B., Chenu, K., Chapman, S., Christopher, J.T., Stone, R.C., Frederiks, T.M. and Alam, G.M.M. (2017). Economic assessment of wheat breeding options for potential improved levels of post head-emergence frost tolerance. Field Crops Research 213, $75-88$.

Nguyen-Huy, T., Deo, R.C., An-Vo, D.-A., Mushtaq, S. and Khan, S. (2017). Copula-statistical precipitation forecasting model in Australia's Agro-ecological Zones. Agricultural Water Management 191, 153-172.

Power, B. and Cacho, O.J. (2014). Identifying risk-efficient strategies using stochastic frontier analysis and simulation: An application to irrigated cropping in Australia. Agricultural Systems 125, 23-32.

Russell, J. (1990). Effect of interactions between available water and solar radiation on sugarcane productivity and the impact of climatic change. Proceedings of the Australian Society of Sugar Cane Technologists $12,29-38$.

Sugar Research Australia (2014). 2014 edition of the irrigation of sugarcane manual published in 1998 by BSES Limited.

Sugar Research Australia (2017). Variety guides 2016-17. http://www.sugarresearch.com.au/page/Growing_cane/Varieties/Publications/.

Valle, H. and Martin, P. (2015). Australian sugarcane farm businesses: financial performance, $2013-14$. Research report by ABARES. 